\title{
NAS TOPOGRAFIAS DE UM ENCONTRO: MOVÊNCIAS COLETIVAS DE UMA TIPOGRAFIA PATAXÓ
}

\author{
LAURA CASTRO ${ }^{1}$ \\ CACÁ FONSECA ${ }^{2}$
}

\begin{abstract}
RESUMO
Movendo-se entre uma constelação de encontros, entre professores e estudantes do Ensino Superior e Básico, entre a rede de artistas do coletivo gráfico Sociedade da Prensa e o Colégio Estadual Kijetxawê Zabelê, das comunidades pataxó de Cumuruxatiba e sujeitos vindos de diferentes lugares da Bahia e do Brasil, este artigo se põe a pensar quais terrenos e confluências foram acionados na criação coletiva de uma tipografia pataxó. Denominada pela comunidade de ATXÚHU KAÍ, é um alfabeto pataxó constituído a partir de uma série de carimbos artesanais em madeira, produzidos em encontros de saberes, conduzidos pela professora, artista e coordenadora pedagógica Rita Pataxó. Nos elos entre aldeia, escola indígena e universidade, o texto percorre os vetores de um processo criativo coletivo, em que se descortinam movimentos de uma contra-colonização epistêmica.
\end{abstract}

\section{PALAVRAS-CHAVE \\ Pataxó; Tipografia; Criação coletiva; Artes Gráficas; Aldeia Kaí.}

\section{IN THE TOPOGRAPHIES OF AN ENCOUNTER: COLLECTIVE MOVEMENTS OF A PATAXÓ TYPOGRAPHY}

\begin{abstract}
Moving between a constellation of meetings, between teachers and students of Higher and Basic Education, between the network of graphic artists collective Sociedade da Prensa and the State School Kijetxawê Zabelê, from the Pataxó communities of Cumuruxatiba and people from different places in Bahia and from Brazil, this article begins to think about which terrains and confluences were triggered in the collective creation of a Pataxó typography. Named ATXÚHU KAÍ by the community, it is a Pataxó alphabet made up of a series of handcrafted wooden stamps, produced in meetings of knowledge, conducted by the teacher, artist and pedagogical coordinator Rita Pataxó. In the links between village, indigenous school and university, the text goes through the vectors of a collective creative process, in which movements of an epistemic anti-colonization are revealed.
\end{abstract}

\section{KEYWORDS}

Pataxó; Typography; Collective creation; Graphic Art; Kaí village.

\footnotetext{
1 Doutora em Artes Cênicas (UFBA), com mestrado em Literatura e graduação em Letras pela Universidade de Brasília (UnB). Professora adjunta no Instituto de Humanidades, Artes e Ciências (IHAC) da Universidade Federal da Bahia (UFBA), atua no PROFARTES - Mestrado Profissional em Artes, do IHAC/UFBA e no Programa de Pós-graduação em Artes Visuais - PPGAV/UFBA.

2 Doutora e mestra em Arquitetura e Urbanismo pela Universidade Federal da Bahia e graduada em Design pela Universidade Federal de Uberlândia. Professora Adjunta do Departamento de Artes Visuais da Universidade Federal da Paraíba, onde atua no grupo de pesquisa Entrópicos.
} 


\section{RESUMÉ}

Se déplacer entre une constellation de rencontres, entre enseignants et étudiants de l'enseignement supérieur et de base, entre le réseau d'artistes du collectif graphique Sociedade da Prensa et le Colégio Estadual Kijetxawê Zabelê, des communautés Pataxó de Cumuruxatiba et des sujets de différents endroits de Bahia et du Brésil, cet article commence à réfléchir aux terrains et confluences qui ont été déclenchés dans la création collective d'une typographie Pataxó. Nommé par la communauté ATXÚHU KAÍ, il s'agit d'un alphabet Pataxó composé d'une série de tampons en bois fabriqués à la main, produits lors de rencontres de connaissances, sous la direction de l'enseignante, artiste et coordinatrice pédagogique Rita Pataxó. Dans les liens entre village, école indigène et université, le texte passe par les vecteurs d'un processus créatif collectif, dans lequel se révèlent les mouvements d'une contre-colonisation épistémique.

\section{MOTS-CLÉS}

Pataxó; Typographie; Création collective; Graphique; Village de Kaí.

\section{EN LAS TOPOGRAFIAS DE UN ENCUENTRO: MOVIMIENTOS COLECTIVOS DE UNA TIPOGRAFÍA PATAXÓ}

\section{RESUMEN}

Moviéndose entre una constelación de reuniones, entre docentes y estudiantes de Educación Superior y Básica, entre la red de artistas del colectivo gráfico Sociedade da Prensa y el Colégio Estadual Kijetxawê Zabelê, de las comunidades Pataxó de Cumuruxatiba y sujetos de diferentes lugares de Bahía. y desde Brasil, este artículo inclinarse a pensar qué terrenos y confluencias se desencadenaron en la creación colectiva de una tipografía Pataxó. Nombrado por la comunidad ATXÚHU KAÍ, es un alfabeto Pataxó compuesto por una serie de sellos de madera hechos a mano, producidos en reuniones de conocimiento, realizados por la maestra, artista y coordinadora pedagógica Rita Pataxó. En los vínculos entre el pueblo, la escuela indígena y la universidad, el texto pasa por los vectores de un proceso creativo colectivo, en el que se revelan los movimientos de una contra-colonización epistémica.

\section{Palabras clave}

Pataxó; Tipografía; Creación colectiva; Artes gráficas; Pueblo de Kaí. 


\section{AMÁLGAMA DE PRESENÇAS}

Esse texto é guiado pela imagem da pedra arremessada na água, momento em que se forma um epicentro de ondas sucessivas, concêntricas, sutis. Sobretudo esse texto fala de um movimento visível, plástico, de encontro entre dois corpos, um pesado, duro, rígido, o outro fluido e movente. A pedra toca a água, água vibra ondas, ondas propagam forças como efeito momentâneo, é delicado, reflexivo e poético. É feito imagem de movimento e sedimento, água segue em fluxo, pedra decanta e deposita-se ao fundo. Depois não se sabe mais da pedra, suposto elemento estático, as ondas desaparecem, o rio, represa, ou outro corpo hídrico qualquer plasma sua própria superfície, sempre outra, ora espelho, ora barro, ora manto. Só há uma coisa sem interesse, quem arremessou a pedra?

Uma vez no fundo, o movimento, aparentemente inerte, aparece de tempos e tempos. Grandes viagens são possíveis, do rio ao oceano. Correntezas, fluxos, trânsitos, vento, seres vivos. A pedrinha miudinha, mineral, vai sendo levada e passa a povoar proximidades e lonjuras uma vez nas profundezas. Musgo verde e tudo mais que decanta, passa a ser amálgama vivo, um corpo que dança no mundo hidrosférico. Na condensação da matéria orgânica, aglomerações vitais, uma multidão microscópica de indivíduos. Comunidades de minerais e vegetações onde a vida verde e as moléculas minerais transitam instáveis, recebem constantemente novas formas de permanência. A pedra vira um corpo coletivo: ela, que tanto bate até que fura, vira vida: grafa seu percurso no espaço, corporaliza suas alterações, efeito de sua presença, numa topografia passageira, sutil e infraperceptível.

A experiência do sutil e do infrapecpetível rege uma constelação de relações entre professores e estudantes do Ensino Superior e Básico, a rede de artistas do coletivo gráfico Sociedade da Prensa e o Colégio Estadual Kijetxawê Zabelê, das comunidades pataxó de Cumuruxatiba e sujeitos vindos de diferentes lugares da Bahia e do Brasil, todos envolvidos no projeto de extensão "EDIÇÕES ZABELÊ: produção de materiais didáticos em escolas indígenas". Uma constelação guiada pelo desafio de realizar um livro coletivo que nascesse do encontro, em contextos de oficinas e trocas de saberes, em que a escola e sua comunidade fossem as protagonistas desta publicação, juntamente com as histórias de seu território indígena e especificamente da Aldeia Kaí.

Esse texto narra o encontro com a professora e coordenadora pedagógica Rita Pataxó, artista gráfica, têxtil, artesã de multi linguagens contemporâneas e ancestrais. Seus saberes e fazeres detém uma dimensão vital e geradora da criação do livro coletivo, sobre a qual nos debruçamos a seguir. Caminhamos pelos encontros entre gravura e alfabeto, letra e borracha, 
carimbo e grafismo pataxó, impressões e virtualidades, um colégio estadual indígena e algumas universidades públicas brasileiras, livros e tecidos, artistas e professores, entre crianças e adultos. Desta caminhada nasce o ATXÚHU KAÍ, nome dado pela comunidade a um alfabeto pataxó constituído a partir de uma série de carimbos artesanais em madeira em Cumuruxatiba, tornado depois uma tipografia, a disposição visual de uma fonte. A grande matriz desse alfabeto é o encontro com a poética de Rita Pataxó, que colaborou também com a elaboração do presente texto, a partir de uma entrevista realizada dois anos após o lançamento do livro ${ }^{3}$.

Encontro como potência de afetação, como acontecimento regido pela alteridade, como abertura de um outro em nós, como acionamento de diferenças, como desestratificação de sentidos. Encontro como acontecimento, algo paradoxalmente prosaico e muito excepcional, aquele momento de perceber algo estranhamente novo e velho, parece um encontro com o outro e com a gente mesmo. E esse parece mais um aprendizado especificamente com o povo pataxó, da comunidade da Aldeia Kaí, em Cumuruxatiba, no Município de Prado.

Como nas imagens de uma "Educação pela Pedra", em todo movimento de seu trajeto, de sua viagem, nos colocamos mais especificamente em reunir lições de tudo que é possível ver acontecer a partir do encontro, acontecimento que incendeia afetos e presenças, corporalizado na união do carimbo sobre o papel. Tudo isso que aqui surge em torno da carnadura concreta desse alfabeto, sua voz premente de escritas sobre escritas, por onde nasce fontes e frentes de luta na disputa de narrativas, no seio do Extremo Sul da Bahia. Como a pedra que leciona, na didática de João Cabral de Melo Neto, ela entranha uma série de agenciamentos das etapas desta criação coletiva (CABRAL, 1966, p. 20-21).

\section{CAMINHOS ABERTOS: A UFSB E 0 EXTREMO SUL DA BAHIA}

É muito importante situar que o encontro aqui narrado é fruto das experiências acontecidas no âmbito do projeto de extensão "EDIÇÕES ZABELÊ: produção de materiais didáticos em escolas indígenas", vinculado ao Instituto de Humanidades, Artes e Ciências, do Campus Paulo Freire, na Universidade Federal do Sul da Bahia (UFSB) ${ }^{4}$.

\footnotetext{
${ }^{3}$ A entrevista foi realizada entre os dias 24 e 25 de março de 2021 e encontra-se integralmente publicada em http://www.edicoeszabele.com.br/2021/04/entrevista-com-mestra-rita-pataxo.html

4 O projeto de extensão "EDIÇÕES ZABELÊ: produção de materiais didáticos em escolas indígenas", vinculava-se ao Instituto de Humanidades, Artes e Ciências, do Campus Paulo Freire, da Universidade Federal do Sul da Bahia (UFSB), contava com docentes de diferentes campi da UFSB assim como com a colaboração docente da Universidade do Estado da Bahia (UNEB) e da Universidade Federal de Goiás (UFG).
} 
Em primeiro plano, é premente situar o contexto de criação da UFSB, fortemente influenciado por ideias relativas a uma "universidade nova", pautadas pela democratização do acesso. Mas sobretudo, contra a produção do conhecimento disciplinar, homogêneo e organizacionalmente hierárquico, com um "processo de produção relativamente descontextualizado em relação às premências e do cotidiano das sociedades" (SANTOS; ALMEIDA FILHO, 2008, p. 40).

O plano orientador ${ }^{5}$ da universidade foi um documento elaborado pela Comissão de Implantação, da instituição recém-criada por um projeto de lei sancionado pela Presidenta Dilma Rousseff em 2013. Com base em dados parciais e informações preliminares sobre contexto e demanda, com uma série de versões preliminares postas em consulta pública, esse documento se configurou, inicialmente, como uma espécie de documento-base filosófico e conceitual da UFSB, com sua última versão aprovada em 2014, pelo conselho universitário pro tempore.

Como uma compilação de princípios e alicerces teóricos do projeto institucional e político-pedagógico convocava sua comunidade, sobretudo docentes, a uma ideia de interiorização do ensino superior público, tendo como um de seus princípios o desenvolvimento regional. Isso implicava pensar em cursos que não tivessem distanciados das especificidades e demandas locais, assim como não criassem uma cobertura territorial limitada, provocando, por isso, o isolamento dos pequenos municípios e localidades remotas, muitos deles assentamentos rurais, comunidades indígenas e quilombolas.

Além disso, a noção de "ecologia dos saberes", de Boaventura de Souza Santos, neste sentido, um dos marcos conceituais do Plano Orientador, incidia nessa espécie de "revolução epistemológica", a favor de uma justiça cognitiva, com a coexistência dos saberes populares e produzidos no âmbito de culturas não-ocidentais confrontando-se com os conhecimentos historicamente tidos como científicos. Como um conjunto de práticas, ela implicaria:

"uma vasta gama de ações de valorização, tanto do conhecimento científico, como de outros conhecimentos práticos, cuja partilha por pesquisadores, estudantes e grupos de cidadãos serve de base à criação de comunidades epistêmicas mais amplas que convertem a universidade num espaço público de interconhecimento" (SANTOS; ALMEIDA FILHO, 2008, p. 70).

Importante frisar, neste sentido, que a "ecologia dos saberes" é entendida como um aprofundamento da "pesquisa-ação" que, segundo Boaventura, prevê uma execução participativa de projetos, sendo resultados de pesquisa benéficos também para resoluções de

\footnotetext{
${ }^{5}$ É possível ter acesso ao plano orientador, à carta de fundação e ao estatuto da UFSB no seguinte link: https://www.ufsb.edu.br/a-ufsb/apresentacao-ufsb.
} 
problemas das comunidades envolvidas. Portanto, havia um chamado para pensar em como criar oportunidades para a construção coletiva de saberes, sem a ideia de uma mera transmissão de conhecimentos, que a universidade pudesse criar e abrigar esse ambiente pluriepistêmico.

A UFSB nasce oferecendo, como proposta de um primeiro ciclo de formação, Bacharelados Interdisciplinares em Artes, Humanidades, Ciências e Saúde. Todos os cursos eram oferecidos nos três campi, localizados em diferentes cidades do Sul da Bahia: Itabuna, Porto Seguro e Teixeira de Freitas.

O projeto do curso do Bacharelado Interdisciplinar em Artes, especificamente, que abrigou nosso projeto "Edições Zabelê", também apontava para direções importantes no âmbito do diálogo com os saberes e no campo da partilha do sensivel ${ }^{6}$, na contramão de um curso com uma abordagem isolada e disciplinar, com vias de produzir um conhecimento instrumental. Ao lado da interdisciplinaridade, portanto, figurava no projeto político-pedagógico do curso o conceito de interculturalidade.

Para além de um "sectarismo teórico" tão comum no contexto universitário e no conhecimento curricularmente eurocentrado, a proposição de uma formação justaposta interdisciplinar e intercultural - ia, justamente, ao encontro do processo de criação, reprodução e transmissão dos conhecimentos tradicionais, que não passam pela fragmentação disciplinar (CARVALHO; FLÓREZ FLÓREZ, 2014, p. 132-133).

Sendo assim, propostas como a de Encontro de Saberes notadamente bem sucedidas, como o Encontro de Saberes do Instituto Nacional de Ciência e Tecnologia (INCTI) de Inclusão no Ensino Superior e na Pesquisa da Universidade de Brasília (UnB) e o Programa de Formação Transversal em Saberes Tradicionais da Universidade Federal da Universidade Federal de Minas Gerais (UFMG), eram possíveis de serem vividas na própria estrutura curricular do curso em questão.

Por exemplo, as transversalidades previstas na formação em Artes na UFSB deveriam passar, necessariamente, por diferentes artistas e mestras das comunidades tradicionais do Sul da Bahia. Muitas das atividades de ensino se davam de um modo extensionista, na medida em que muitas experiências didáticas engendravam-se a partir de experiências com os mestres e as mestras dos saberes e a interface entre arte e comunidades. Destacamos, na matriz do curso, o componente curricular "Ateliê Encontro de Saberes", quando todo um período letivo deveria ser dedicado à construção de processos e projetos artísticos dos estudantes a partir do encontro

\footnotetext{
${ }^{6}$ Ver Rancière, 2005.
} 
com mestres e aprendizes de comunidades tradicionais, com investigações teórico-práticas sobre seus sistemas estéticos ${ }^{7}$.

Na prática, havia, portanto, um campo aberto de possibilidades para experimentar outros saberes, assim como questionar o conhecimento universitário eurocêntrico, uma vez que boa parte dos componentes curriculares dialogavam com poéticas e estéticas ameríndias e afrobrasileiras. No bojo do campo das artes, outros questionamentos são ainda possíveis, como o reconhecimento dos artistas populares, o "popular" como um adjetivo que acompanha a noção de "artista", abrindo uma cisão entre alta e baixa cultura, as discussões insuperáveis da distinção entre arte e artesanato, sobretudo em relação aos povos tradicionais, entre outras.

Dessa forma, não há exagero em dizer que, entre 2015 a 2018 ${ }^{8}$, na UFSB havia uma experimentação - no melhor sentido de experimentar o experimental, de Hélio Oiticica - onde se criava um espaço contrahegemônico da "ideia de universidade como uma instância branca, racista e dedicada a reproduzir unicamente o eurocentrismo do saber moderno" (CARVALHO; FLÓREZ FLÓREZ, 2014, p. 139, tradução nossa).

Neste sentido ainda vale pontuar que o território do Extremo Sul da Bahia, onde especificamente era lotado o "Edições Zabelê", o Campus Paulo Freire, composto não apenas por Teixeira de Freitas, mas uma série de outros municípios, é povoado fortemente por uma relação afroindígena. O termo é aqui pensado a partir do que Marcio Goldman propõe:

"Não se pretende apenas designar uma relação que uniria conjuntos "afros" e "indígenas" preexistentes, mas, antes, tomá-la como um modo particular de articular diferenças. Nesse sentido, é a própria relação que é afroindígena e, nesse sentido, como mostram muitos dos textos aqui reunidos, ela não está limitada a esses universos que se convencionou denominar afros e/ou indígenas" (GOLDMAN, 2017, p. 12).

De modo geral, o Sul da Bahia pode ser entendido como um portal central no encontro da colonização brasileira, entre chegadas, expulsões e muito sangue derramado, muita violência. Cunhado no discurso turístico como a "Costa do Descobrimento", palco de muitas cenas de turismo predatório, remonta muitos encontros no bojo dos processos de desterritorialização e

\footnotetext{
7 Importante também pensar, por exemplo, a partir da provocação crítica de Cristine Takuá, as contribuições para além dos domínios do estético. Quando a pensadora guarani diz que a universidade não dialoga com os seres criativos da floresta, como os vegetais e animais, oculta a sabedoria indígena pela ausência dos "diálogos criativos da floresta, sobre os conhecimentos e as filosofias complexas que habitam na vida dos povos tradicionais ancestrais da Terra há muitos séculos. Só que esses saberes não conseguem dialogar diretamente com essa universidade, que escreve tanto e parece que observa pouco a sutileza das diversas formas de transmissão de conhecimento" (TAKUÁ, 2021, p. 2).

${ }^{8}$ Marcamos temporalmente esta avaliação da experiência de ensino com a UFSB, pois a partir de 2018 não tivemos mais ligação de trabalho formal com a universidade.
} 
reterritorialização entre africanos e indígenas, encontros esses que provocaram uma série de zonas de indiscernibilidades, cruzamentos e modulações.

Neste contexto, os saberes percorriam também caminhos imprevisíveis nessa relação, assim como as comunidades. Tanto a comunidade quilombola de Helvécia quanto a comunidade indígena de Cumuruxatiba tinham, temporalmente, retomadas relativamente recentes de seus territórios, datadas a partir de 2000:

"Vemos surgir uma variedade de povos virtuais que se atualizam no Nordeste, no Sudeste e na várzea amazônica: as diversas comunidades de pequenos agricultores, pescadores, sertanejos e caboclos que se redescobrem indígenas e reivindicam os direitos constitucionais que protegem justamente os 'índios em geral' (...) Esses novos povos estão, na verdade, entre os mais antigos de todos; são reemergência minoritária das minorias indígenas exterminadas ao longo de cinco séculos de colonização da mata atlântica, da caatinga e da calha do Amazonas" (VIVEIROS DE CASTRO, 2019, p. 33).

Enquanto isso, um grupo de artistas vindos de uma região periférica do município de

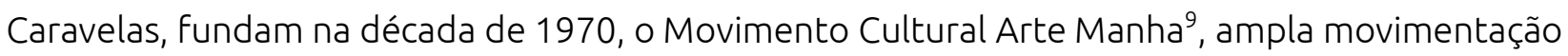
que acontece desde o cinema até a dança, da escultura à serigrafia, do entalhe da madeira à cerâmica, comprometidos não somente com a memória, mas como essa relação afroindígena é fundante e em movimento em suas próprias produções individuais e sobretudo coletivas e locais.

\section{MOVÊNCIAS COLETIVAS: KIJETXAWÊ ZABELÊ E SOCIEDADE DA PRENSA}

O chão do Extremo Sul da Bahia, o entorno de Comexatiba e a instituição Colégio Estadual Indígena Kijetxawê Zabelê - Anexo Kaí assim como os passos que demos em direção a este ajuntamento se fazem também de todas essas confluências. Movências dais quais, de tantas pessoas envolvidas, descortinam meandros espectrais e complexidades impressas também no nosso encontro, que se deu na instância pedagógica da criação artística e também na afetividade deflagrada entre estes dois coletivos-amálgamas, a comunidade escolar da Kijetxawê Zabelê - Anexo Kaí e a equipe de artistas do projeto de extensão "Edições Zabelê".

Uma topografia que se dá provisoriamente no agora da ação de encontrar, ao mesmo tempo que assume uma perenidade no rastro da vida e de tudo que se cria dela, poéticas e estéticas em movimento, em relação, assim como tantas matérias, signos e rastros, disso que Antonio Bispo dos Santos chama de "povos pindorâmicos", que perduram apesar do fogo etnocida da colonização nas Américas (BISPO, 2015, p. 28).

\footnotetext{
${ }^{9}$ Ver Mello (2003).
} 
O Colégio Indígena Kijetxawê Zabelê foi criado a partir da Portaria nº 1181, em 2006, após muitas lutas pelo ensino diferencial da comunidade pataxó do território Kaí-Pequi. Recebeu o nome de uma importante anciã do povo pataxó, Dona Zabelê, Luciana Ferreira, hoje falecida, fundamental na reivindicação por uma escola diferenciada e intercultural. O colégio é nucleado em seis aldeias, sendo uma delas a Aldeia Kaí. A comunidade escolar é formada por estudantes desde o Ensino Infantil até a Educação de Jovens e Adultos. O grupo de professores inclui indígenas da aldeia e não-indígenas, moradores de Cumuruxatiba ${ }^{10}$.

O projeto "Edições Zabelê", gestado desde 2016, teve como uma das principais interlocutoras do processo Rita Pataxó, que era também diretora do Colégio Estadual Indígena Kijetxawê Zabelê na época. Nosso primeiro contato foi quando, em janeiro de 2016, a aldeia sofreu uma violenta e humilhante reintegração de posse que destruiu todas as ocas, casas, plantações e um posto de saúde. Por volta de 100 policiais federais e militares invadiram a área, expulsando a comunidade do seu território, cumprindo o mandado de reintegração de posse favorável à suposta proprietária da terra, outorgado no ano de 2015. Eram muito nítidas as marcas da devastação e todo o sofrimento dos pataxó que ali viviam. Depois da destruição das construções, havia acontecido uma retomada feita pelas mulheres do território que possibilitou que eles retornassem ao local da aldeia ${ }^{11}$.

Naquela época, em meio às narrativas e ao cenário de devastação, uma coisa intrigava no território arrasado pela violenta reintegração de posse. Apenas a escola Zabelê na Aldeia Kaí havia sobrevivido aos tratores e servia agora de cozinha, de quarto, de habitação para muitos. Como o colégio é estadual, naquele momento de pé, ela apontava uma saída estratégica para o fortalecimento do território como um todo. Como revigorar ações junto ao colégio poderia contribuir na luta para assegurar também aquele território, naquele momento tão instável e arriscado? Fazer um livro então, no âmbito de um projeto de extensão, com a comunidade escolar para essa e outras comunidades escolares, indígenas e não indígenas, figurou como uma tática transversal ${ }^{12}$ que propusemos a essa comunidade. Rita Pataxó relata como o livro e seu processo criativo atravessou a comunidade, que estava maculada por esse trauma:

"(...) esse momento que o livro chegou na comunidade, a importância desse momento, porque a comunidade, tinha sofrido uma reintegração de posse onde toda a comunidade, aluno, família estavam desesperados, sabe? Desesperançado de refazer, estavam todo mundo pensando em desistir. Então o livro chegou pra dar essa reerguida, essa reanimada

\footnotetext{
${ }^{10}$ Ver Oliveira e Silva (2017).

11 Ver Pataxó, J. (2019) e Mipây'ré'pâx suniatá'xó (2021).

${ }^{12}$ Para ler mais desse processo, ver Castro (2019).
} 
em toda comunidade, tanto criança, quanto anciões, quanto os jovens, que já não estavam querendo estudar mais, porque você imagina uma criança que veio de estudar debaixo de uma árvore e daí de repente a comunidade com todo seu recurso, tirando de bolsa família, tirando da boca dos seus filhos, constrói uma sala mais ou menos adequada, que mesmo assim com todo esforço não era uma sala adequada. Aí essas famílias constroem essa sala pra esses alunos, esses alunos já estão ali acostumados, sentindo felizes com aquela salinha, mesmo não tendo piso, mas tudo rebocadinho e tal, de repente vem a reintegração, acaba com tudo e as crianças tem que voltar de novo pra debaixo da árvore pra estudar, imagina só? Imagine se na cabeça do adulto isso já fica difícil de processar, imagine uma criança que naquele momento ali da idade dela, que ela mais memoriza, entendeu? Sem contar a violência que as crianças já tinham sofrido de ver homens armados entrar dentro de uma sala de aula em pleno horário de aula, mandando as crianças sair tudo pra fora, com arma em posição. A criança ver patrola, derrubando sua casinha e a criança querendo enfiar debaixo da patrola para ser destruído junto com a casa, sabe? (...) Então a partir do momento que o projeto chegou e o livro começou a ser executado, as crianças começaram a ter aquela vontade que elas não estavam tendo mais, as crianças não estavam tendo mais vontade de estudar, nem de ir pra escola, nem de sair mais de casa. Qualquer polícia que passava na rua elas pensavam que já tava vindo pra dentro da comunidade, as crianças ficaram com aquele terror na mente, e o livro foi tirando isso, foi tirando, foi tirando com aquelas brincadeiras, com aquelas oficinas" (PATAXÓ, R. s/p, 2021).

Do nosso lado, além de acadêmicos, éramos, artistas agregados pelo coletivo Sociedade da Prensa. Esse ajuntamento interessado em antigos ofícios gráficos - prensas, tipografias e impressões artesanais - tinha seu ponto de ação no Centro Antigo de Salvador, atuando na cena independente da cidade, sobretudo a partir de seu ateliê no Santo Antônio Além do Carmo, onde, na época, os artistas visuais Tiago Ribeiro, Flávio Oliveira e o músico Prince Addamo, um "filho da terra", sul-baiano de Camacã, trabalhavam especialmente com serigrafia. A Prensa contava com seus "sócios", artistas, mas também professores do Ensino Superior, a designer Cacá Fonseca, docente na Faculdade de Artes Visuais da Universidade de Goiás - UFG, o poeta Márcio Junqueira, professor do Curso de Letras na Universidade do Estado da Bahia e as docentes do Bacharelado Interdisciplinar em Artes, da UFSB, Laura Castro e Cinara de Araújo, que traziam consigo seus estudantes da região, especialmente de Teixeira de Freitas.

Esse coletivo, junto com a comunidade escolar, formava o que chamamos posteriormente de uma espécie de residência artístico-pedagógica. Tivemos dois ciclos de convivências diárias a partir do colégio, no ano de 2018, com ciclos de oficinas e trocas de saberes, residindo em Cumuruxatiba, a pleno vapor com o processo criativo de um livro por vir. É importante pontuar como esse encontro reverbera no fazer de Rita Pataxó e no seu saber-fazer como artista criadora:

"Foi a maior felicidade quando vocês entraram dentro da nossa comunidade, dentro da nossa escola, pra abrir esse espaço pra gente expor esse conhecimento. Então ali foi uma troca de conhecimento e tanto a gente passou o nosso conhecimento, como nós recebemos de vocês e isso foi um incentivo que vocês deram pra gente. Eu não ganhei assim nenhuma coisa financeiramente falando, mas nós ganhamos muito mais que foi a divulgação desse trabalho que a partir disso aí, as pessoas veio a reconhecer o meu 
trabalho, valorizar esses carimbos. Quando eu vi que o que eu, a partir de uma criação minha, essa criação está se espalhando para outras pessoas, não só na minha escola e já tá fluindo até fora do Brasil, esse livro tá, inclusive que esse verão já veio pessoas de outros países atrás desse livro" (PATAXÓ, R. s/p, 2021).

\section{ESCRITAS SOBRE ESCRITAS}

A Sociedade da Prensa, naquela época, tocava uma pesquisa com especial interesse no carimbo, como entusiastas da impressão manual. O encontro com Rita Pataxó, por isso, foi extremamente apaixonante. Rita cria bolsas, roupas e diversos produtos estampados com esta técnica, com cores e grafismos indígenas. Exercita como poética cotidiana o ofício de uma designer e artista têxtil, produz roupas para crianças, adultos, turistas e cria os figurinos dos grupo de cantoras da comunidade "Mipâ'irá PAz Suniatáxxó - Meninas Sentir no Canto". O processo de trabalho de Rita Pataxó pode ser pensada como uma manufatura ímpar, sua estamparia nasce de carimbos confeccionados com restos de madeira do rio, borracha EVA industrializada e cola. Os carimbos atualizam grafismos e geometrias indígenas em um suporte inédito. A seguir, a mestra nos conta como foi o desenvolvimento de seus primeiros carimbos, em entrevista concedida a nós:

Imagem 1. Carimbo e estamparias impressas em tecido por Rita Pataxó.

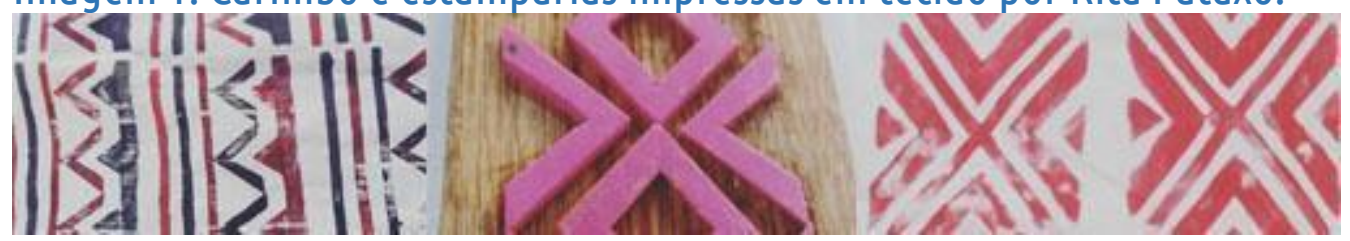

Fonte: Acervo do projeto Edições Zabelê

"Aí eu conversando com essa colega, ela falou assim, Rita você pinta à mão, é trabalhoso. Ela disse assim, porque você não pensa numa coisa que seja mais rápida, mesmo que seja manual, mas que seja mais rápido? Você por exemplo, pinta 10 traços de uma vez, 15 traços de uma vez sabe? Aí fiquei pensando naquilo. Como que pode ser? Aí comecei a trabalhar na escola e, trabalhando na escola comecei a ter acesso a carimbos, carimbos desses que você carimba em alguma coisa, sabe, carimbo? Desses que tem a plaquinha quadrada que você coloca o carimbo e bate lá. Então eu falei assim, eu posso fazer um carimbo. Aí eu pensei, como eu vou criar esse carimbo? Aí fiquei pensando como eu criaria esse carimbo, tentei com isopor. Vou pegar um isopor, fazer uns traços, vou desenhar a pintura e tentar bater com isopor. Aí não deu certo. Aí eu falei, o que eu posso fazer? Apareceu aqui na escola uma doação da prefeitura de Prado, na época, aí olhei pro EVA, apertei o EVA, esse negócio aqui pode dar certo. Mas como que eu vou fazer? E eu pensei, ah já sei, peguei uma madeirinha, fiz a pintura primeiro no caderno de desenho, vi que a pintura ficou bonita, aí pedi pra meu irmão cortar uns pedacinhos de madeira pra mim. Meu irmão cortou, aí eu fiz cortando o EVA com a tesoura depois vi com estilete fica mais prático. Depois eu fui só melhorando, aí cortei o EVA na forma das pinturas, como você viu que eu fiz aqui na oficina do projeto. Cortei e fui colando na madeira, aí coloco a tinta, começo pintar o EVA ali na madeira. Aí fui testando as cores. As vezes quando a gente pinta, suja e, a cada pintura tem que limpar o carimbo, tipo eu pinto um tecido inteiro, aí 
eu tenho que limpar aquele carimbo pra tinta não estragar e por aí vai, pra eu reutilizar, pra não ser uma coisa descartável, pra ser uma coisa que eu faço e reutilizo ele" (PATAXÓ,

R. s/p, 2021).

O carimbo também pode ser entendido como uma técnica de impressão artesanal, que independe de grandes maquinários. No caso dos carimbos de Rita, isso era evidente. Rita Pataxó gravurista, com seus carimbos matrizes transporta os grafismos para uma ferramenta de natureza industrializada e serializada. Mas não apenas. O carimbo é artefato ancestral, a palavra 'Kirimbu'13 tem origem banto no quimbundo e é um dos tantos trânsitos diaspóricos incorporados no português do Brasil. Kirimbu é inscrição na pele de marcas de origens, indicando pertenças ancestrais às milhares de tribos africanas; o tráfico de negros escravizados expropriou essas inscrições ancestrais para tornar kirimbu sentido e marca de propriedade de corpos negros e sistemas de taxação de impostos. De escoriações da cosmologia ancestral para as marcas de título de propriedade. De kirimbu nasce carimbo e nas intensivas transições de significados, carimbo torna-se sistema de personalização de correspondência e ferramenta elementar de reprodutibilidade técnica.

Por outro lado, há correspondência com processos produtivos da própria Sociedade da Prensa, que num tempo muito recente havia adquirido uma máquina de fazer carimbos como desejo de ampliação de seu repertório de tecnologias artesanais de impressão. A Sociedade da Presa comprou uma máquina de carimbo, Rita Pataxó cria seu próprio agenciamento maquínico, é residual e inventivo. Os carimbos de Rita Pataxó são matrizes de grafismos em escalas diversas, matrizes de estamparia que, a partir desse encontro, derivaram também em matrizes de tipografia.

O efeito de oscilação, delicado e tênue, do encontro acima narrado, na pedra lançada, é responsável pelo que depois toma nome de ATXÚHU. Sua criação artística no âmbito desse coletivo de sujeitos em torno da produção de um livro - ainda desconhecido, mas desejado por muitos - engendra-se como contingência de tudo que não pode ser previsto. Saberes e fazeres subsidiam aqui uma prática pedagógica para todos os envolvidos, em que a experimentação é a grande tônica; e, congregam dimensões ontológicas da arte contemporânea: o acaso, a experiência, o processo como âmago, a interface entre arte e vida. Estar atento a cada etapa dessa construção é importante para que isso fique claro. Recapitulamos, assim, as etapas do processo pedagógico e criativo.

Primeiramente, organizamos uma oficina em que Rita pudesse, enquanto mestra do saber, ensinar a professores, estudantes e aos artistas envolvidos no projeto seu modo próprio

\footnotetext{
${ }^{13}$ Ver Lopes (2006).
} 
de fazer carimbos. Com madeiras e borracha, ficamos uma tarde fazendo diversos carimbos a partir de estampas de grafismos pataxó. Os grafismos eram criados com as borrachas EVA e dispostos/colados nas madeiras. Feita essa oficina, havíamos criado uma série de mais ou menos 20 a 30 carimbos com grafismos feitos pelos estudantes e professores da Aldeia Kaí, mas também por nós, como aprendizes do encontro. Com aquele conjunto de imagens possíveis, a partir de muitas conversas e de processos criativos que já estavam em curso, decidimos propor uma segunda oficina, dessa vez para compor letras do alfabeto com esses carimbos.

O carimbaço, como chamamos este momento, constitui-se como um agenciamento de corpos, uma espécie de manufatura intergeracional. Éramos crianças de 9 anos até professores e professoras de mais de 50 anos experimentando a reprodutibilidade técnica. Carimbaço tipográfico, coletividade agremiada na secretaria da escola, nos fundos da casa de Rita Pataxó, onde ela exercia suas funções na administração da escola. Cada singularidade, sujeito, ser, pessoa, dedicava-se à carimbar as letras iniciais de seus nomes e tramar conexões das mais diversas com as letras que passavam pela impressão.

Nesse momento, estávamos maravilhados com um alfabeto inteiro composto por letras grandes, impressas em papel cartolina. Encadernamos e finalizamos um primeiro livro, exemplar único, em formato agigantado, cada letra tinha em média $40 \mathrm{~cm}$ de altura. Em seguida, a equipe do projeto digitalizou a imagem das letras e inicialmente compusemos um pequeno livro artesanal com elas, que chamamos de livroalfabeto e reproduzimos em um tiragem maior, ao todo foram impressos e encadernados 200 livros. Agora as letras eram pequenas, tinham em média $10 \mathrm{~cm}$, por outro lado, guardavam a possibilidade da distribuição, dissipação.

Elaborado nas fogueiras de junho de 2018, havia a dúvida do título da obra. Qual nome teria esse livro, que à primeira vista e literalmente foi chamado por nós de livroalfabeto? Entretanto, esse título era sintomático de apenas uma dimensão do livro, o conteúdo que eram as letras, mas o corpo das letras eram grafismos, densidades visuais com grafias de cosmologias ancestrais. Chamar de livroalfabeto parecia render-se à lógica texto centrada do Ocidente. A partir de então, iniciamos um debate com a comunidade escolar da Aldeia Kaí para nomear este alfabeto e o próprio livro. No patxohã, língua pataxó em insistente processo de retomada, não havia uma palavra correspondente. Foi quando surgiu a ideia de ATXÚHU que significa "linguajar" em patxohã. O linguajar é como toma forma uma língua e foi este nome escolhido pela comunidade. 


\section{Imagem 2 - Capa e miolo do livro ATXÚHU KAí}

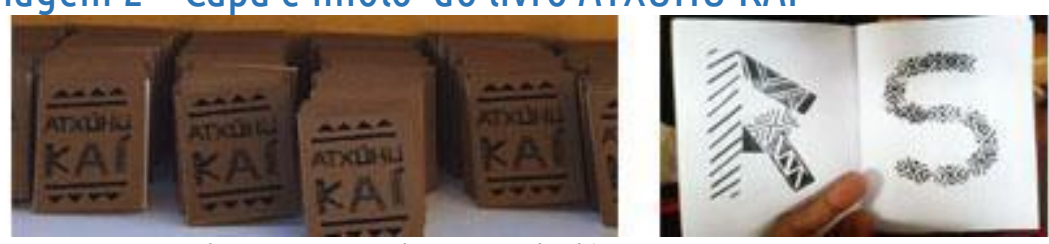

Fonte: Acervo do projeto Edições Zabelê

Posteriormente, Victor Fabem, estudante de Artes da UFSB, participante do projeto, transformou o alfabeto do ATXÚHU KAí em uma fonte de computador, com nome homônimo. A fonte pode ser baixada gratuitamente no site ${ }^{14}$ do projeto e funciona em qualquer processador de texto, como o Microsoft Word, por exemplo. A tipografia depois foi a grande guia do texto do livro que viria a nascer, responsável também pela identidade visual da publicação final, revelando-se, em muitas instâncias, como tecnologia.

"A intelectualidade indígena não está apenas na elaboração do pensamento que acontece na cabeça. Está na elaboração do conhecimento produzido a partir das mãos, das práticas e de todo o corpo. Todo corpo é território e está em movimento, desde o passado até o futuro. É aí que a intelectualidade indígena acontece. (...) O forte do nosso povo sempre foi a oralidade, mas, com as tecnologias, a ampliação dos registros se torna possível, nos trazendo algumas vantagens. Através de fotografias, da escrita digital e da grafia audiovisual, trabalhamos para que as próximas gerações tenham também oportunidade de reativar nossas memórias, compreendendo os diversos atravessamentos históricos vividos pelos Xakriabá" (XACRIABÁ, 2020, s/p).

Podemos evidenciar no ATXÚHU KAÍ uma série de passagens - trocas, deslocamentos e traduções - entre saberes tradicionais e novas formas de compor tais saberes para a potência do livro, como Célia Xacriabá nos provoca nessa passagem, quando fala da fotografia, escrita digital e do audiovisual. O ATXÚHU KAí foi criado pela sobreposição dos grafismos e das letras, buscando o que podemos chamar de conhecimento intercultural concreto, incorporado pelos processos do encontro de outros saberes e de outras técnicas. O "Kaí" era justamente a marca, a topografia do lugar, de um livro-lugar, como chamamos, que encarnava em sua apresentação seu lugar de fundação, a Aldeia Kaí.

Рага muitos, os grafismos e as pinturas corporais são escritas dos povos indígenas. Como salienta a historiadora da arte, Els Lagrou, estudiosa dos povos indígenas, os desenhos gráficos presentes tanto nos artefatos quanto nas pinturas corporais são não somente figurativos, mas também representam as relações entre as diversas formas visíveis e invisíveis inscritas na cosmovisão do povo Huni Kuin. Os grafismos não são somente símbolos, mas a maioria dos desenhos marca a concepção de escrita ao invocar figuras e coisas, mas também

\footnotetext{
${ }^{14}$ www.edicoeszabele.com.br
} 
caminhos e percepções para conceber realidades (LAGROU, 2009). Rita Pataxó, nos relatou dimensões confluentes ao nos contar um sonho:

"Essa ideia de se descobrir, de se criar, de acordo com o que você vai fazendo as pinturas, os traços, aquilo vai ficando mais claro e na sua mente, da sua memória, dentro de você, que é dentro de mim no caso, vai surgindo outros traços. Agora mesmo eu fiz pinturas aqui, que eu ainda não expus no carimbo por falta dessas borrachas mesmo incríveis, as pinturas veio, na realidade, eu durmo e sonho com algumas coisas. Na verdade, esses tempos aí, tem mais ou menos um mês, por exemplo, eu estava dormindo, e aí daqui a pouco começou a vir em sonho aqueles traços no céu, aquelas pinturas. Mais de mil pinturas apareciam na minha mente, como se fosse no céu, em formato de folha, em formato de insetos, em formato de pássaro, em formato de peixe. Assim, não ега o formato do peixe, mas quando você olhava, eu via lá fundo, dava aquela forma que eu conseguia passar pro caderno. Outras eu não consegui e, de acordo com o que eu ia fazendo, a primeira ia aparecendo a segunda, a terceira, sucessivamente. Como aqui é uma casa muito frequentada que ainda tem essa coisa de Secretaria de escola, que vem muita criança, muita professora, aí eu não tenho aquele tempo de ficar concentrada escrevendo, se eu tivesse um lugar que eu pudesse ficar concentrada, você não imagina. Você vê o pouco de tempo que eu fiquei concentrada eu fiz umas pinturas aqui que eu vou tirar foto pra mostrar pra você. Uma pintura, Laura, que você nunca viu na sua vida. Tipo o que significa aquela pintura, aí foi aparecendo assim no sonho, foi aparecendo, foi aparecendo quando eu ainda acordei com aquelas listras assim na minha cabeça, com aqueles traços, fechava o olho, abria. Quando eu abria o olho, eu continuava ainda vendo, aí eu fui no outro dia transcrever pro livro, aí eu consegui transcrever alguns e tem outras que é como se eu estivesse vendo agora, mas eu preciso de tempo, tanto é que eu vou fazer um livro de pintura minha, entendeu? Eu vou fazer um livro de pintura minha. Isso vem assim é um dom mesmo, é um dom, a palavra certa mesmo pra dizer, é o dom" (PATAXÓ, R. s/p, 2021).

Além dessa relação com o grafismo, Maria Inês de Almeida, em seu livro Desocidentada, experiência literária em terra indígena, diz que será justamente a letra que marca o elemento comum entre a literatura ocidental e as literaturas, por ela denominadas, extraocidentais. A letra em sua materialidade, como elemento tipográfico, é o que mantém a escrita literária como memória viva. A autora coteja os espaços dos grafismos com o elemento tipográfico que irá "assegurar a vitalidade dos traços de um povo" (ALMEIDA, 2009, p. 44).

Impressos neste alfabeto, portanto, no ATXUHÚ, estão as memórias e os afetos gerados por este encontro. Dessas letras se desdobram palavras de resistência e narrativas de retomada. Escritas sobre escritas da própria experiência de criação coletiva. 
Imagem 3. Letras Tipografia ATXUHU KAI no Microsoft Word.

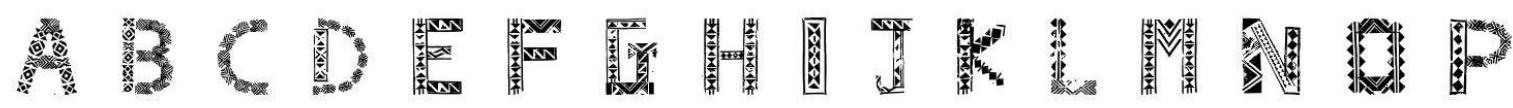 TIPOLYAFA PATAXÓ ATHUHL KAI}

Fonte: Acervo do projeto Edições Zabelê.

\section{FONTES E FRENTES: TRAVESSIAS ALFABÉTICAS}

Ailton Krenak nos chama atenção em relação aos povos de tradição oral e sua travessia para o mundo da escrita. De como também, historicamente, a leitura e a escrita chegam como instrumento da colonização dos jesuítas e talvez a bíblia seja o primeiro livro que funda essa relação de imposição da cultura branca sobre os povos originários, ou seja, a relação da catequização através do mundo da leitura e escrita. Em seguida, Krenak diz:

"Enquanto os índios puderam resistir, eles não aprenderam nem a ler, nem a escrever. Então seria interessante a gente investigar se quando os índios estão lendo e escrevendo se eles já se renderam ou se eles ainda estão resistindo" (KRENAK, 2016, vídeo).

O alfabeto pataxó ATXÚHU pode ser pensado como um processo estético-político da comunidade escolar da Aldeia Kaí, assim como uma travessia coletiva carimbada, gravada, fruto de um encontro de saberes entre professores, estudantes, artistas, indígenas e não indígenas. Aqui as ondulações fluidas das topografias narradas nos encontros entre a UFSB e as comunidades do Extremos Sul da Bahia, o Colégio Estadual Indígena Kijetxawe Zabelê e a Sociedade da Prensa, atualizam a imagem da pedra arremessada na água, cujos movimentos configuram vetores acionados como uma contra-colonização epistêmica. Numa conjuntura educativa em que a universidade participa, mas não é ela quem conduz os conhecimentos, muito pelo contrário. Ela, no que toca aos seus representantes, é agente, mas sobretudo aprendiz. É nesse contexto que vemos nascer um alfabeto de escritas indígenas, não alfabéticas, não interpretável, que coexiste, como enfrentamento ao puríssimo BÊABÁ impresso da língua portuguesa, mantendo vivos esses tensionamentos e sobreimpressões, sendo fonte, sendo frente de luta (CARVALHO; FLÓREZ FLÓREZ, 2014, p. 133). 
Durante o lançamento do livro, fruto do projeto, o Kijetaxawê Zabelê - Aldeia Kaí, em cerimônia emocionante, foi momento de perceber a vitalidade e os desdobramentos também do ATXÚHU KAÍ. O alfabeto pataxó encontrava-se na sala de alfabetização. Era o alfabeto impresso com a fonte Atxuhú Kaí, fixada em todo contorno da parede A de ...., B de ..., C de ..., $D$ de dendê, $E$ de .... até o Z de Zabelê! O ATXÚHU KAí impresso também nos papéis que sinalizavam os nomes das salas e das turmas do colégio.

Imagem 4. Mural da sala de alfabetização do Colégio Estadual Kijetxawê Zabelê - Anexo Kaí

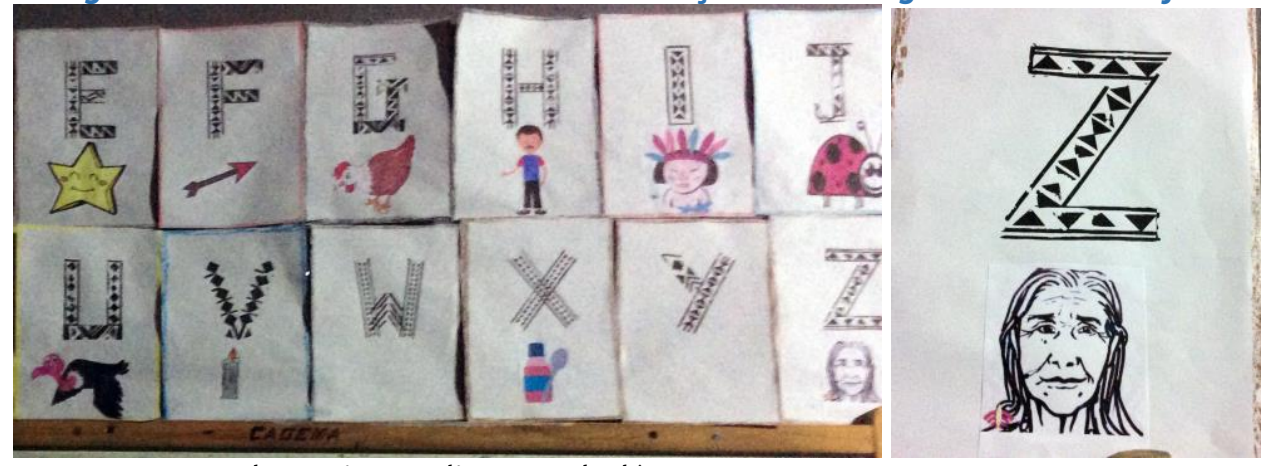

Fonte: Acervo do projeto Edições Zabelê.

Outro reencontro ainda, no suporte e materialidade mais originários, егa um forro de mesa carimbado com a palavra PATAXÓ, peça feita por Rita. Era uma espécie de peça cerimonial e de destaque, cobria a mesa de abertura, espaço de liturgia e maior visibilidade do evento de lançamento. Neste caso, eram os mesmos carimbos da estamparia, as ferramentas originais de Rita agora acionados como as matrizes para a tipografia. Um ritornelo sutil, pois parecia que sempre estivera ali. Essa peça é um testemunho do encontro e troca entre a Sociedade da Prensa e Rita Pataxó. Troca como metamorfose da estamparia em tipografia. Nessa peça, como o processo era de uma gravura, as cores vermelho, preto e verde se recoloriam numa mistura de cores impuras e matizadas entre si. A toalha-bandeira PATAXÓ afirmando sobre a instituição mesa a atmosfera primorosa de uma rara cerimônia: o lançamento de um livro pataxó. 
Imagem 5. Um dos forros carimbados, no lançamento da publicação final

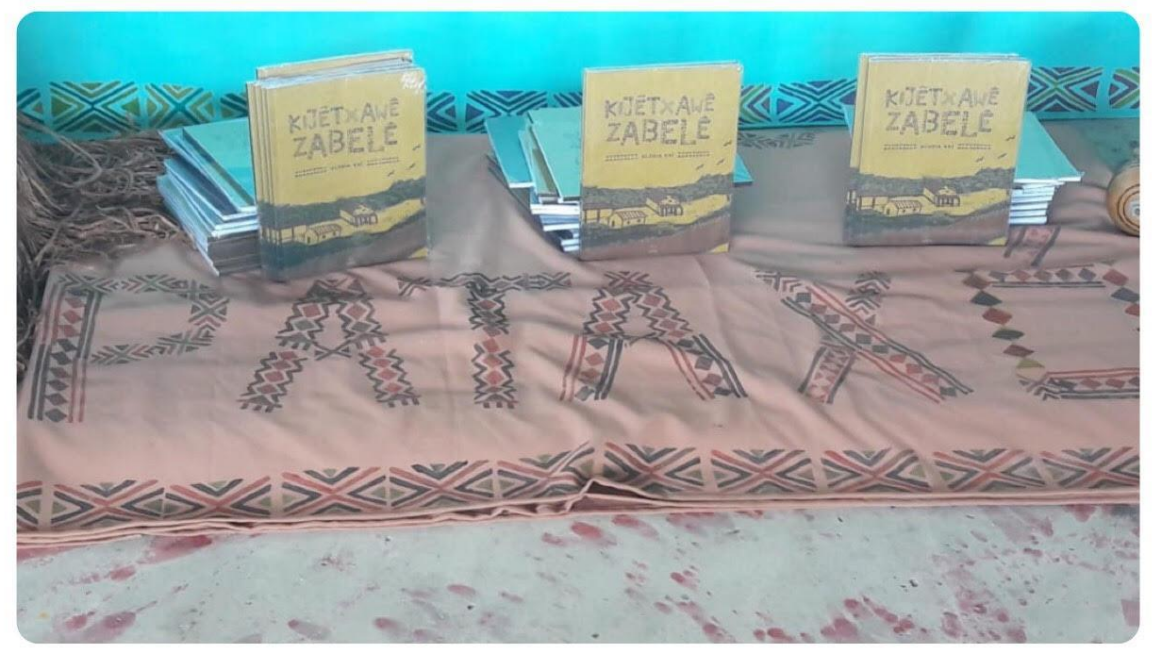

Fonte: Acervo do projeto Edições Zabelê.

Esses reencontros com o ATXÚHU KAí suscitaram um sentido de troca como metamorfose e não como intercâmbio. No intercâmbio configura-se um objeto em troca de outro, isso como um sistema recorrente nas narrativas dos colonizadores e que tem nos espelhos uma figura síntese do uso da troca deliberadamente como enganação, usurpação e expropriação. Isso seria o caso de Rita ter trocado o carimbo por um livro da Sociedade da Prensa, apontando para um processo em que cada parte envolvida na troca segue com o seu objeto privado, de uso individual e íntegro nas suas propriedades. A troca-metamorfose operada entre nós explicita plasticidade-visceralidade, não se tratava de um suporte material, mas de um saber-fazer enredado num campo de mutações dos próprios saberes-fazeres.

A troca aqui pensada instaura um campo onde se materializa um comum, como um amálgama entre os sentidos, as partes e os mecanismos de ambos lados envolvidos. Isso já aponta para uma expansão filosófica da ideia de troca, rumo à prática da reciprocidade e da partilha, cuja confluência aponta para troca como metamorfose. Dessas que os bichos perdem o exoesqueleto, couro, pele, para encorparem outro, mais vivo, mais resistente, acionando, desse modo, uma cosmologia mais anímica e menos econômica. Os carimbos metamorfoseados em tipografia, metamorfoseada em artesanato pataxó, metamorfoseada em código informacional para downloads, metamorfoseado em ferramenta de alfabetização e sinalização do espaço, metamorfoseada em bandeira, cujos devires apontam para um campo expandido de processos de criação amalgamado em torno de encontros sensíveis, moventes, guiados pela escuta e pela 
partilha. Rita Pataxó direciona nosso olhar para a relação entre o que o livro guarda como fonte de memória viva:

\begin{abstract}
"Estar no livro é essa sensação de que eu fiz o que eu me dediquei a minha vida inteira vai ser passado não só pra uma nem duas pessoas, não só pra uma nem duas famílias, mas vai se passar pra quem sabe o mundo inteiro, né? Então essa é a sensação. É aquilo mesmo que te falei, ver tudo que eu fiz, tudo que criei ser colocado num livro onde várias pessoas vão ter acesso, vão conhecer, ter o conhecimento, isso nos traz mesmo essa sensação de ser valorizado, de saber que isso vai ficar, saber que não vai morrer quando a gente morrer, saber que vai ter a possibilidade de outras pessoas usarem, sabe? Pra mim é assim. Porque não adianta a gente saber, ter tanta sabedoria, inteligência, entendimento e aquilo ficar só pra nós, pra mim não adianta. É como se fosse ficar, como se fica alguma coisa muito bonita, num quarto fechado onde não vai ter ninguém pra admirar, né?" (PATAXÓ, R. s/p, 2021).
\end{abstract}

Ao sentido de troca a professora Maria Geovanda Batista, do Centro de Pesquisas Interculturais da Temática Indígena (UNEB), em um evento de lançamento do livro propôs a imagem do arremesso de uma pedra na água. Gesto que desencadeia esse campo vibracional de reverberações concêntricas, círculos em torno de círculos em torno de círculos em torno de ... de ... de ... ondulam a superfície da água, intensidades sutis colocam em movimento forças visíveis, outras sensiveis e outras ainda, moleculares, à imagem de mutações. Relacionamos essas reverberações que ondulam a superfície como esse movimento-fluxo das metamorfoses do carimbo como transmutação e vida, fazer vivo grafado no livro, suporte que sedimenta ao

mesmo tempo que movimenta. É a imagem da pedra arremessada e da água. A água, essa territorialidade fluxo e densa, o povo pataxó, particularmente a água-aldeia-kaí; a pedra, o livro, esse fragmento de exterioridade disparadora de mutações, posto à prova do tempo e de suas funduras; os círculos e a roda das mutações à imagem da brincadeira, do jogo, do awê, ele mesmo como proposta de criação editorial: o encontro, de onde nasce o livro.

\title{
REFERÊNCIAS
}

ALMEIDA, Maria Inês de. Desocidentada - experiência literária em terra indígena. Belo Horizonte: Editora UFMG, 2009.

BISPO, Antônio. Colonização, quilombos: modos e significados. Brasília: INCT/UnB, 2015.

CASTRO, Laura. 0 que pode um livro?. In: CASTRO, Laura, FONSECA, Caca. (Org.). Kijetxawê Zabelê: Aldeia Kaí. 1ed.Salvador: Sociedade da Prensa/EDTÓRA, 2019. p. 106-110.

CARVALHO, José Jorge; FLÓREZ FLÓREZ, Juliana. Encuentro de saberes: proyecto para decolonizar el conocimiento universitario eurocéntrico. Nómadas, n. 41, 2014, p. 131-147. 
GOLDMAN, Marcio. Contradiscursos Afroindígenas sobre Mistura, Sincretismo e Mestiçagem Estudos Etnográficos. Revista de @ntropologia da UFSCar, v. 9, n. 2, p. 11-28, 2017.

KRENAK, Ailton. Ailton Krenak: culturas indígenas, 2016. Disponível em: https://www.youtube.com/watch?v=LEw7n-v6gZA Acesso em 27 de abril de 2020.

LAGROU, Els. A Arte Indígena no Brasil: agência, alteridade e relação. Belo Horizonte: C/ Arte, 2009.

LOPES, Nei. Novo Dicionário Banto do Brasil. Rio de Janeiro: Pallas, 2006.

MELLO, Cecília Campello do Amaral. Obras de Arte e Conceitos: Cultura e Antropologia do Ponto de Vista de um Grupo Afro-Indígena do Sul da Bahia. Dissertação de Mestrado em Antropologia Social. PPGASMuseu Nacional, Universidade Federal do Rio de Janeiro, 2003.

OLIVEIRA, Cristiane Maria de; SILVA, Paulo de Tássio Borges da. Voos na Sabedoria: 0 ensino do Patxohã na Escola Estadual Indígena Kijetxawê Zabelê. In: ZAPAROLI, Witembergue Gomes (0rg.). Caminhos e Encontros na Educação de Indígenas. 1 ed. Imperatriz-MA: Editora Ethos, 2017. p. 327-347.

MIPÂY'RÉ'PÂX SUNIATÁ'XÓ. Negra Índia. In: LOBO, Jade Alcantara et al. Revista Odù: Contracolonialidade e Oralitura. Ilhéus: Fundação Cultural do Estado da Bahia, p. 81, 2021.

PATAXÓ, Jandaia. Retomada do território. In: CASTRO, Laura, FONSECA, Caca. (0rg.). Kijetxawê Zabelê: Aldeia Kaí. 1ed.Salvador: Sociedade da Prensa/EDTÓRA, 2019. p. 18-19.

PATAXÓ, Rita. Entrevista com a mestra Rita Pataxó. Disponível em: http://www.edicoeszabele.com.br/2021/04/entrevista-com-mestra-rita-pataxo.html Acesso em 09 de abril de 2021.

RANCIÈRE, Jacques. A partilha do sensível: estética e política. Ed. 34, 2005.

SANTOS, Boaventura de Souza, ALMEIDA FILHO, Naomar. A Universidade no século XXI: para uma universidade nova. Coimbra: Almedina; 2008.

TAKUÁ, Cristine. Seres criativos da floresta, 2020. Disponível em: http://selvagemciclo.com.br/wpcontent/uploads/2020/11/CADERNO_4_TAKUA.pdf Acesso em 2 de janeiro de 2021.

VIVEIROS DE CASTRO, Eduardo. Brasil, o país do futuro do pretérito. São Paulo: n-1 edições, 2019.

XAKRIABÁ, Célia. Amansar o giz. PISEAGRAMA, n. 14, p. 110 - 117, 2020.

Recebido em 28 de junho de 2020. Aprovado em 18 de março de 2021. 